\title{
Antioxidative activity of extracts from Mengkudu (Morinda citrifolia L.) root, fruit and leaf
}

\begin{abstract}
This study was conducted to evaluate the antioxidative activity of extracts from different parts of Mengkudu (Morinda citrifolia L.), including leaf, fruit and root. Methanol and ethyl acetate were used as solvents and antioxidative effects measured by a ferric thiocyanate method (FTC) and thiobarbituric acid test (TBA). The methanol extract of Mengkudu root exhibited high antioxidative activity that was not significantly $(\mathrm{P}<0.05)$ different from $\alpha$ tocopherol or butylated hydroxyl toluene (BHT), while the methanol extracts of fruit and leaf showed negligible activities. On the other hand, the ethyl acetate extract of all parts of Mengkudu exhibited significant antioxidative activity, which is comparable to that of both $\alpha$ tocopherol and BHT. Similar trends of antioxidant activity were observed using either the FTC or TBA methods. Roots showed the highest activity of the parts tested. The results suggest that several compounds contribute to antioxidative activity of different parts of Mengkudu. Activity in the roots may be due to both polar and non-polar compounds but, in the leaf and fruit, only to non-polar compounds. Copyright (C) 2002.
\end{abstract}

Keyword: Antioxidative activity; Morinda citrifolia Linn; Natural antioxidant 